التقنيات المعاصرة ودورها فى بناء التصميم ثلاثى الأبعاد

إعلداد

شيما ء كحمد الدسوقى عتمان

مجلة بحوث التربية النوعية ـ جامعة المنصورة

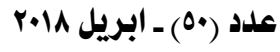




\section{التقنيات المعاصرة ودورها فى بناء التصميم ثلاثى الأبعاد}

إعداد

شيماء محمد الدسوق عتمازن

تناول البحث أهمية التصميم المبتكر وأسس التصميم القائمة علي التقنيات المعاصرة و و

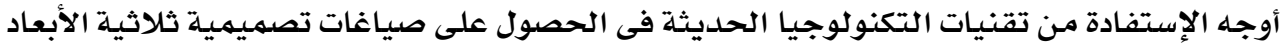

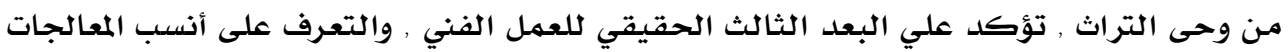

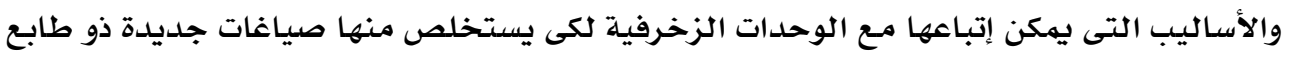

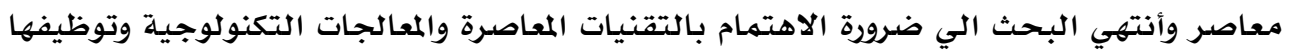

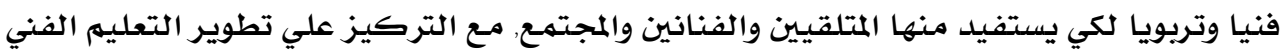

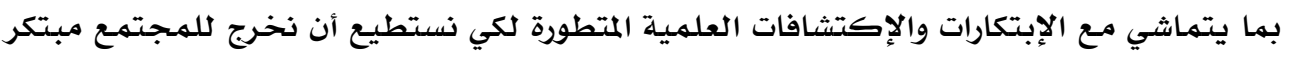

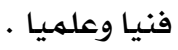

\section{الاقدهمة}

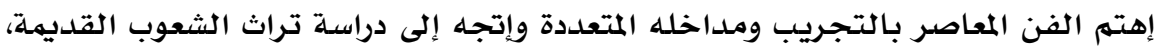

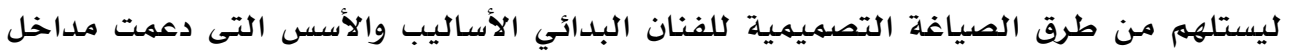
التجريب ومدارس وإتجاهات الفن المعاصر.

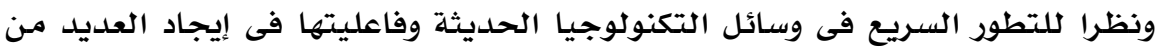

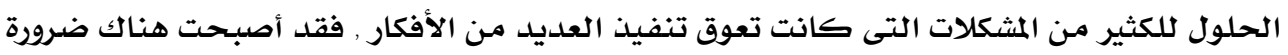

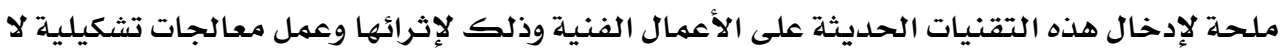

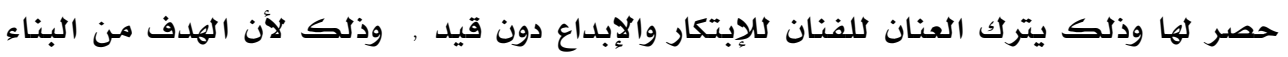

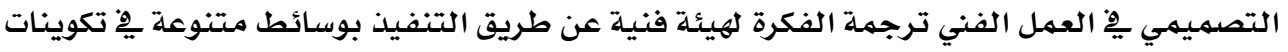

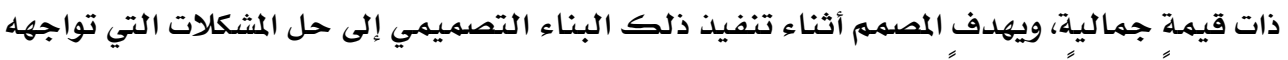
تصميميا، وتقنيا، وجماليا. فالبناء التصميمي قانون تنتظم على أساسه الأجزاء المكونة لهيئة العمل الفني، والمصمهم

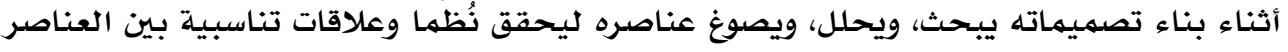

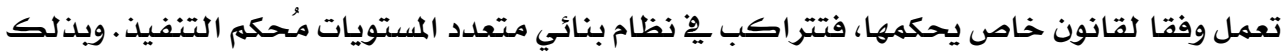


يكون التكوين المتعدد المستويات قد ارتكز يِ طريقة بنائه على أسس وضوابط ترتبط بالبنائية كإتجاه فني منظم تجتمع فيه الأجزاء. إنتشرت فى الفترة الأخيرة تقنية جديدة أطلق عليها تقنية البعد الثالث أو ثلاثية الأبعاد

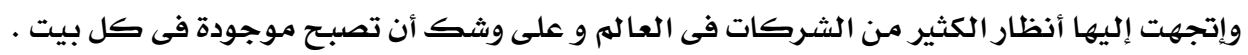

\section{مشكلة البحث:}

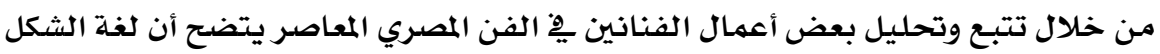

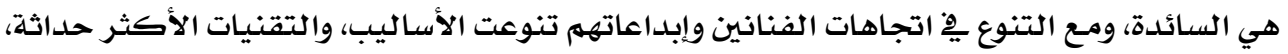

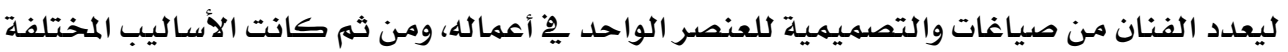

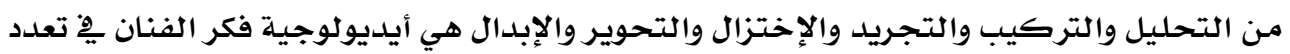

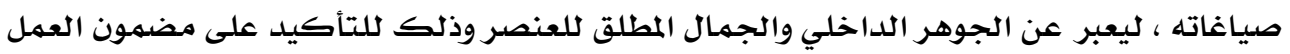

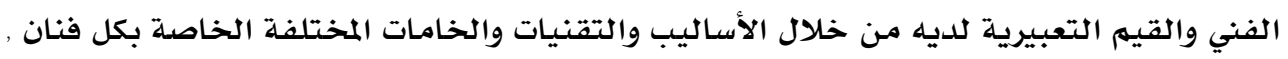

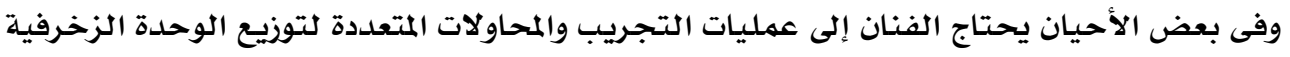

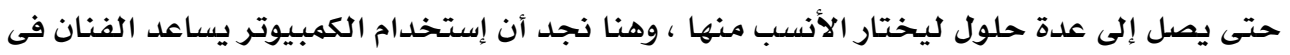

التحكم بمكونات العمل الفنى وتعدد الحلول الفنية وسهولة إختيار العناصر والخامـات والألوان . وتهدف هذه الدراسة إلى توظيف الوحدات والموتيفات الزخرفية بإستخدام جهاز الكمبيوتر

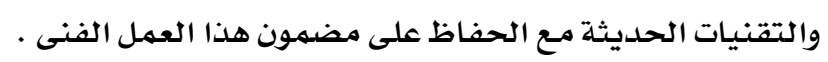

\section{ويناء على ما سبيق بيكن تحديد مشكلة البحث فى الأتى :-}

• ما أوجه الإستفادة من تقنيات التكنولوجيا الحديثة في الحصول على صياغات تصميميلية

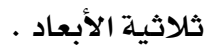

• ما أنسب المعالجات والأسـاليب التى يمكن إتباعها مع الوحدات الزخرفية لكى يستخلص منها

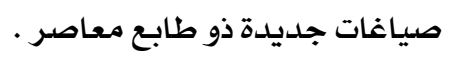

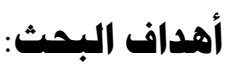

ا. الكثف عن الاتجاهات والأساليب المختلفة ، لتعدد الصياغات التصميمية للعنصر الواحد

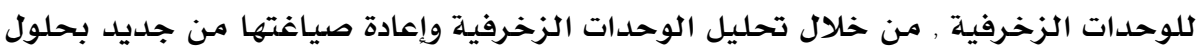

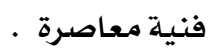

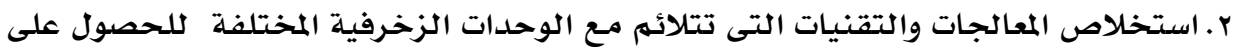

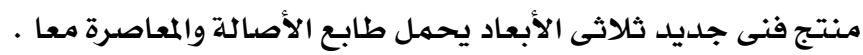

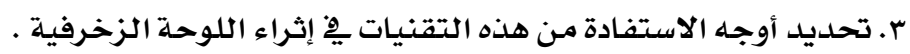




\section{أهمية البحث :}

تبرز أهمية البحث فيما يلى :

- - إحداث تنوع فى التصميمات الفنية عن طريق إستخدام تقنيات البعد الثالث .

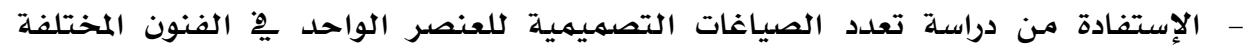

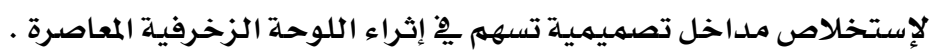

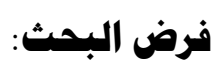

\section{يفترض البحث عدة فروض وهى على النحو التالى :}

يمكن تحقيق قيم جمالية مبتكرة بهزج التراث بالتقنيات الحديثة من خلال برامج الكمبيوتر

$$
\text { كتقنية البعد الثالث . }
$$

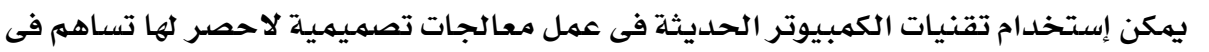

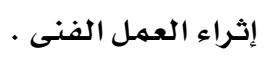

\section{هندمبية البحث:}

يتبع البحث منهجين هما المنهج الوصفى التحليلي والمنهج التجريبي على النحو التالى :

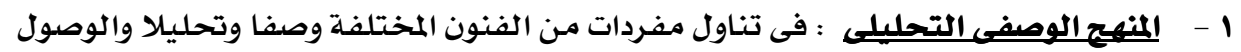

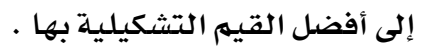

r - المنهج التجرييى : وفيه تقوم الباحثة بعمل تجارب ذاتية لتحقيق هدف البحث والتأكد من

$$
\text { صدق فروضسه . }
$$

وذلك من خلال الدراسـة النظرية والتطبيقية من خلال :-

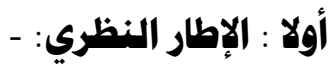

أـ دراسلة وحدات وزخارف الفنون المختلفة ومعرفة مدىى ملائمتها لروح العصر الحديث.

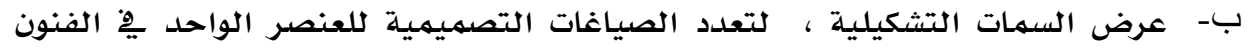

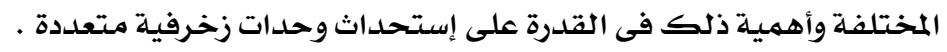

\section{ثانيا : الإطار العهمبي:}

ا. إستحداث تصميمات معاصرة مستمدة من الفنون المختلفة ومعالجتها بإستخدام تقنيات

$$
\text { الأبعاد الثلاثية. }
$$

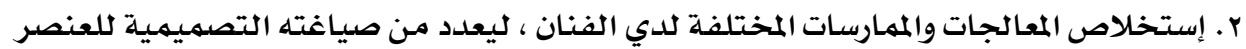

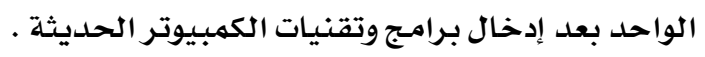

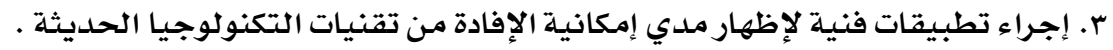




\section{ـ الصياغات التصميمية}

هي كيان له بنية داخلية وخارجية (عنصر) مر على مجموعة من المعالجات الشكلية

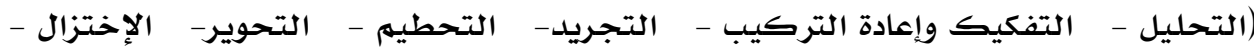

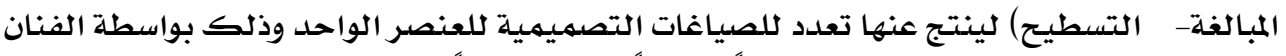

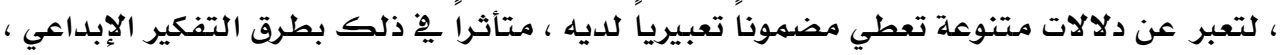

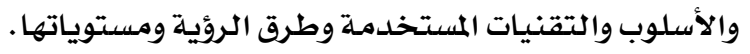

ـ التقنية (Technique)

هى لفظة مشتقة من اللفظة الإغريقية الدالة على (الفن) ويمكن تعريفها بطريقة

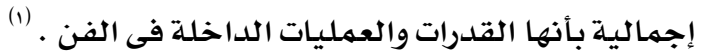

وللتقنية مفاهيم كثيرة وتعرف حسب موقعها فى الإستخدام فى المجالات والأنشطة

المختلفة فى الحياة , وفى مجال الفن يرى البعض أن التقنية تعنى المهارة فى إستخدام الأدوات ,

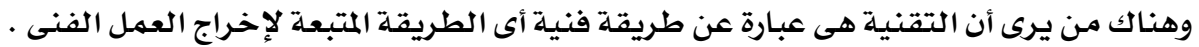

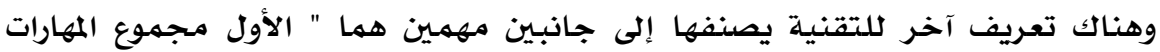

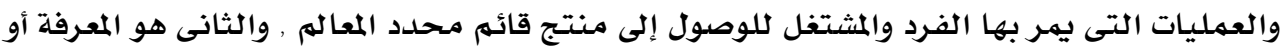

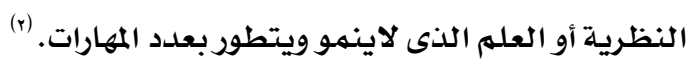

ويمكن تعريف التقنية على أنها " قدرة المصمهم على إستخدام أدوات العمل وخاماته

إستخداما يجعلها تحقق الغرض منها.

ـ تقنيات الكمبيوتر :

هى كل الأدوات والأساليب التى تتيحها برامج الكمبيوتر الخاصة بالتصميم والتى تساعد

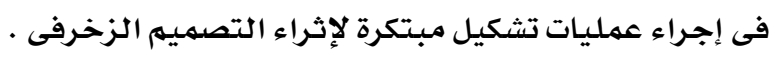

ـ النقطة

وهي كائن عديم الأبعاد, لا طول له ولا مساحة ولا حجه, وإنها لها موقع فقط.

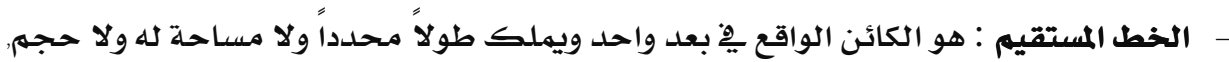

ويتحلدد بنقطتين على الأقل.

(1) إيمان محمد زكى : " الإمكانات الملمسىلة للمعالجات السطحية والإستفادة منها فى إثراء الأسطح الخزفية " , رسالة

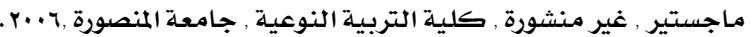

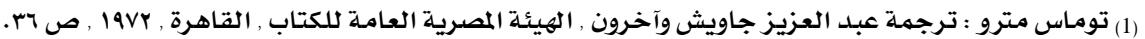

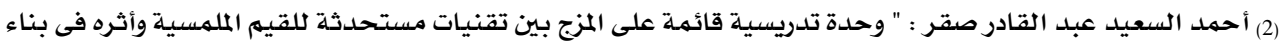

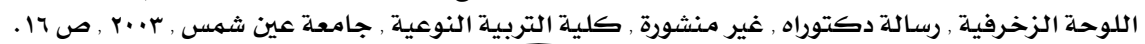




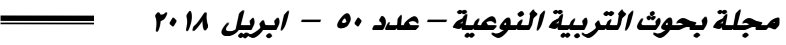

- المستوي : هو سطح ِِّ الفراغ يتواجد ِِّ بعدين اثنين, يملك طولاً وعرضاً, وبالتالي مساحةً,

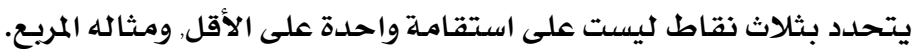

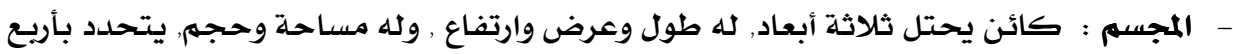

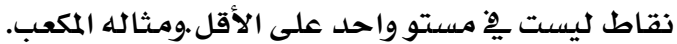

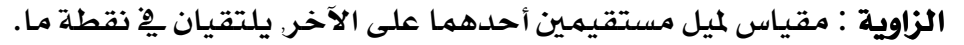

- البعد الثالث:

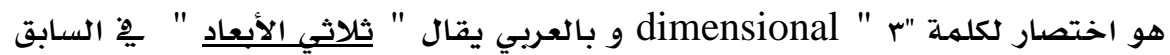

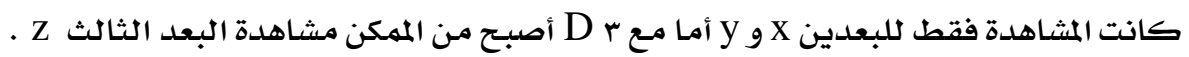

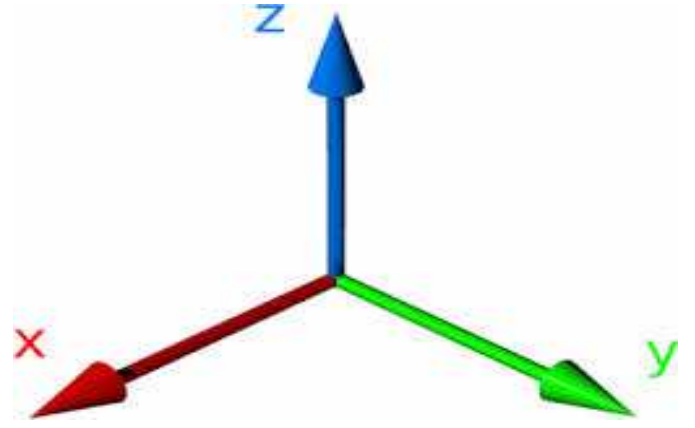

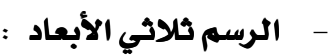

هو رسم المجسمات الحقيقية الموجودة يِّ الطبيعة مـع تبيين أبعادها الثلاثة. وللرسم ثلاثي

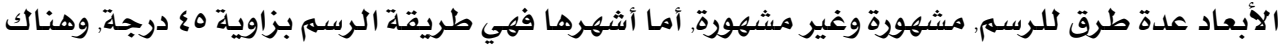

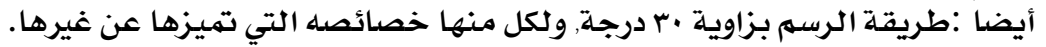

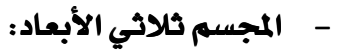

مما شك فيه أن المشاهد لعمل مجسم ذو ثلاثة أبعاد يتطلب منهه أن يتحرك حول العمل

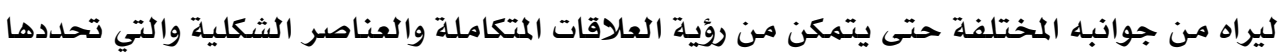

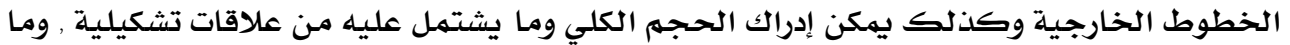
يلي ذلك من رؤية تحليلية لإدراك التفاصيل التركيبية والتعبيرية ، وذلك الكية للتعرف على التهية العنصر

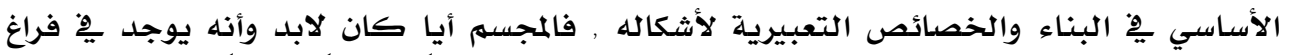

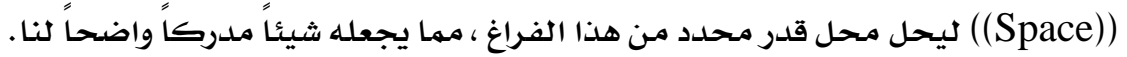

-

"إن الثيء الصلب ، لابد وأن يكون كائناً ِِّ فراغ ، ويحل محل كمية محددة من هذا

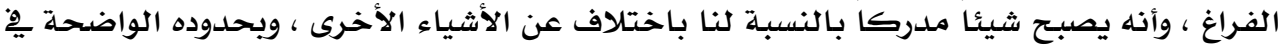




\section{بعنوان (تقنيات تصوير ما بعد الفن الحديث لإثراء التعبير الفني):}

التي تهدف هذه الدراسة إلى تحديد مظاهر العلاقة بين التقنيات الحديثة وما يرتبط بهات التهات

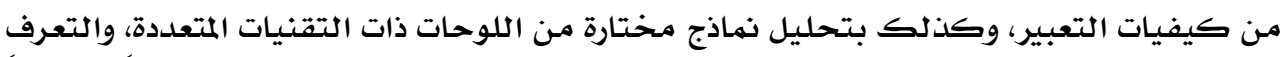

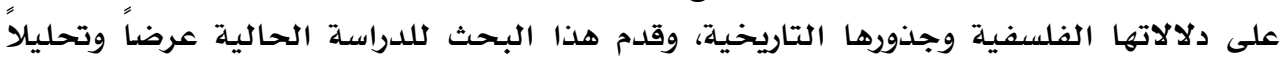

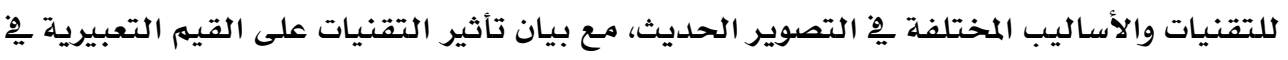
العمل الفني.

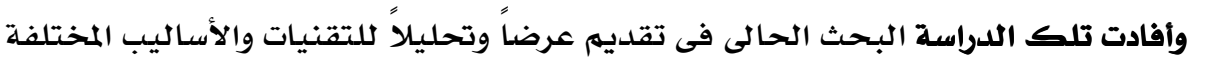

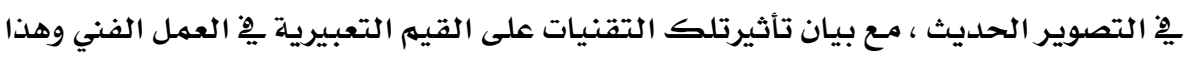

$$
\text { يتفق مـع يسعى إليه البحثث . }
$$

(v)

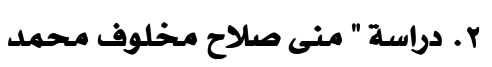

\section{بعنوان ( أساليب وبرامج الكمبيوتر فى أعمال الجرافيك ) :}

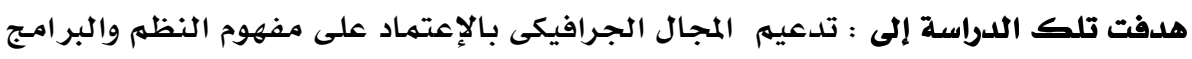

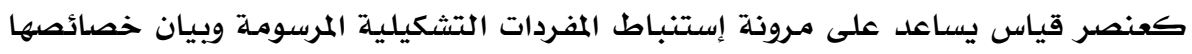

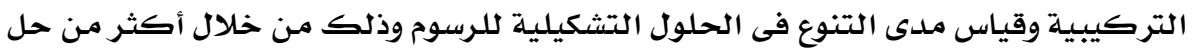

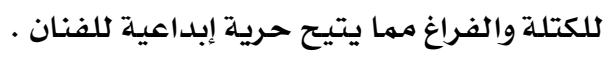

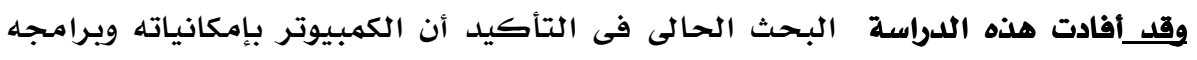

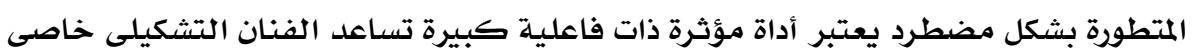

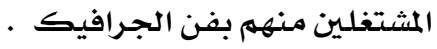

$$
\begin{aligned}
& \text { r. دراسة " فيرا فايز حبشى " (r) }
\end{aligned}
$$

\section{بعنوان ( برامج الحاسب الآلى وأثرها فى التصميم الجرافيكى المرئى ) :}

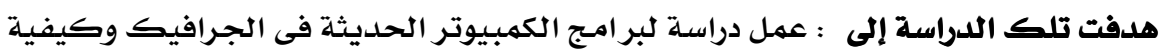

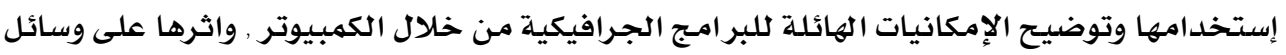

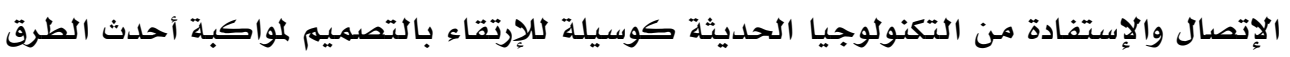

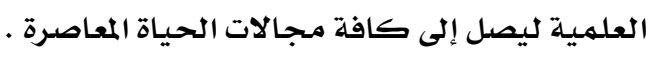
(1) روز رأفت زكي : تقنيات تصوير ما بعد الفن الحديث لإثراء التعبير الفني، رسالة ماجستير، كلية التربية الفنية، (r) منى صلاح ملحة حلوان، 1990.

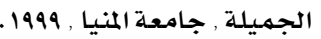
(1) فيرا فايز حبشى : " برامـج الحاسب الآلى وأثرها فى التصميهم الجرافيكى المرئى ", رسالة ماجستير, كلية الفنون

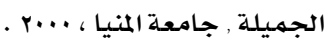


مجلة بحوث التربية النوعية - علد .0 - ابريل 11. P ب

وقد أفادت هذه الدراسة البحث الحالى فى دراسة برامج الجرافيك وإمكانية الإرتقاء

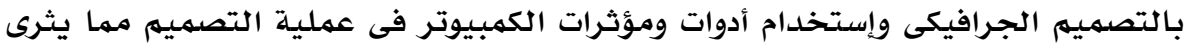

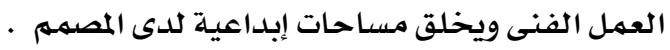

ع. دراسة "أمل محمد فهمى محمود بحيرى" (1) بعنوان (التوظيف الجرافيكى لبصريات الخامة وأثره على جماليات التصميمات الزخرفية):

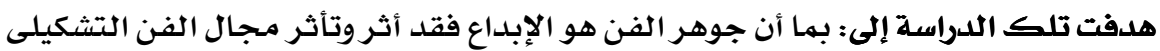

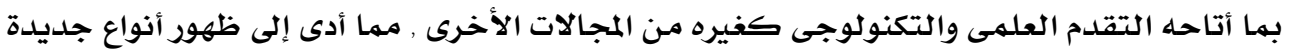

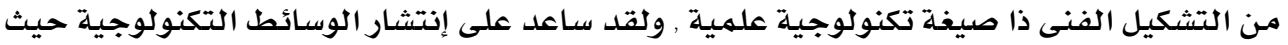

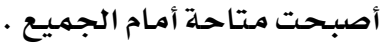
ويمتلك الكمبيوتر إمكانيات متعددة تتيح الفرصدة لإنتاج أعمالا فنية ذات حلول متتنوعة

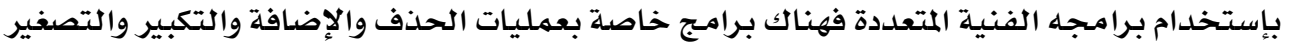

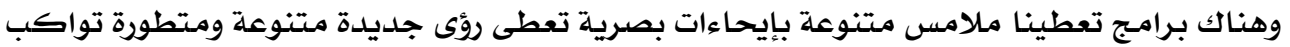

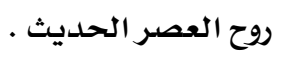
- وقد أفادت هذه الدراسة البحث الحالى فى الخطوات الإجرائية حيث أنها تناولت دور

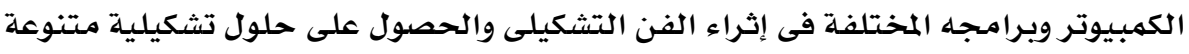

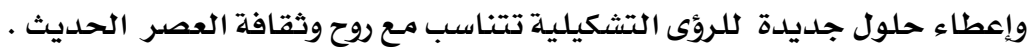
ه. دراسـة "هند عبد الرحمن محمد " بعنوان ( متغيرات العلاقة بين الأثكال الثنائية والثلاثية الأبعاد

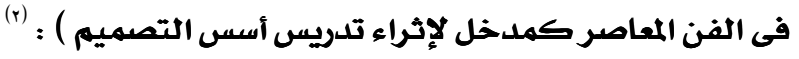

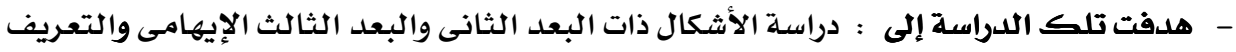

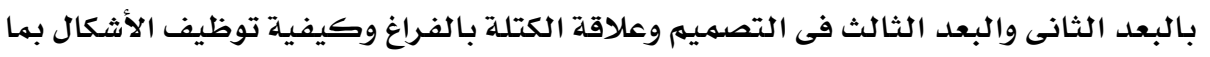

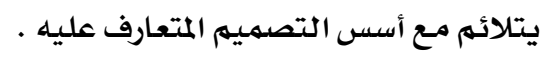

وقد أفادت هذه الدراسة البحث الحالى فى الخطوات الإجرائية حيث أنها دراسة مفصلة

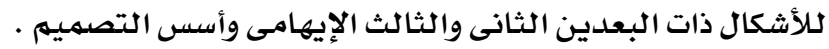
7. دراسة "دروثى (r) (Dorothea)

هدفت تلك الدراسة إلى : تناول بعض الأسس والعناصر فى التصميهم بداية من ترتيب

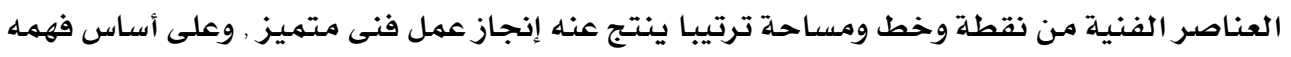
لمقومات العمل الفنى وقدرته على صياغة عناصره. وكذلك يتحديه فند عن التكرار والصور التى

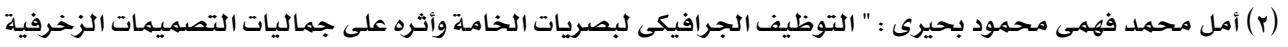

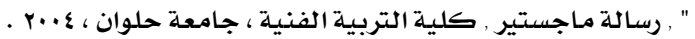

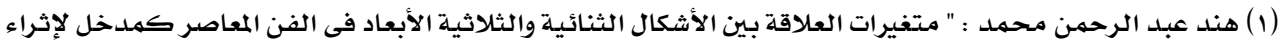

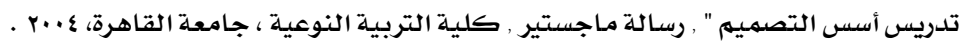

(2)Dorthea : Design Elements and principles , U.S.A , 2005 . 
يتخذها سواء كان ثابتا أو متغير , ويشير إلى الدور الذى تلعبـه الحركة الموجودة بالطبيعة ومدىى

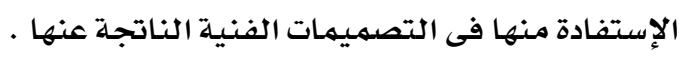

وقد أفادت هذه الدراسة البحث الحالى فى الخطوات الإجرائية حيث أنها تناولت دراسة أسس وعناصر التصميم بشكل تفصيلى وكذلك كيفية تحقيق الوحدة داخل العمل الفنى .

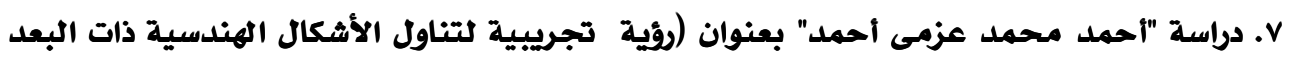

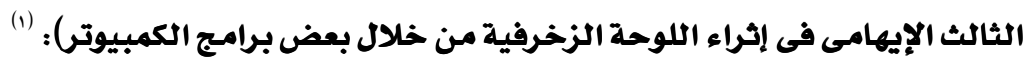

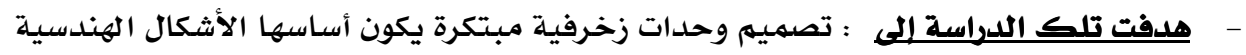

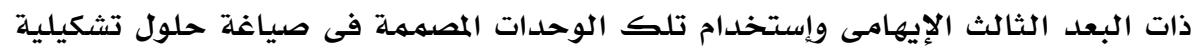

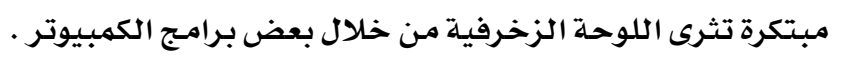

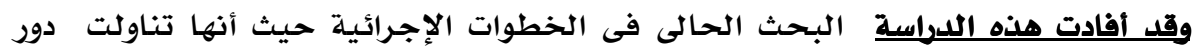

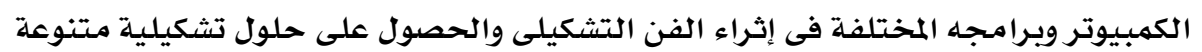

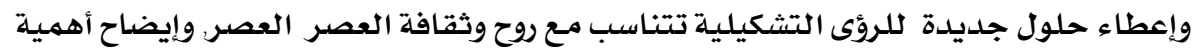

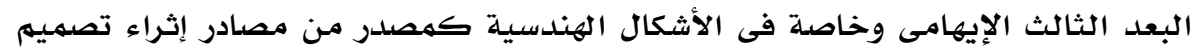

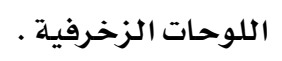

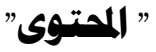

\section{الإفادة من تقنيات التكنولوجيا الحديثة فى الحصول على معالجات تصميمية مبتكرة}

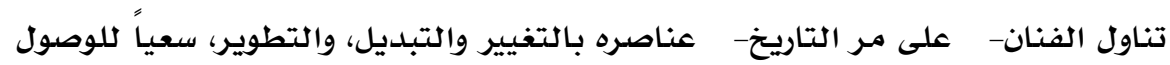

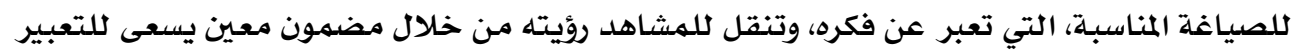

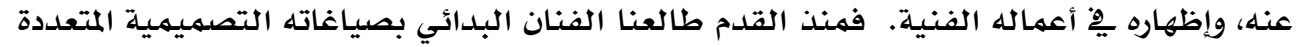

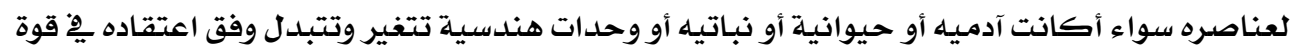

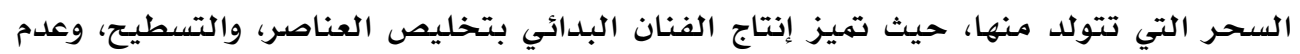

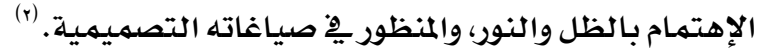

ومـع تطور الزمن أدخل على الفن العديد من التقنيات التى ساهمت في إثراء الأعمال

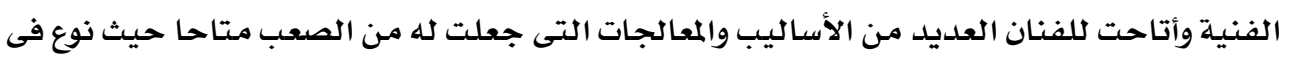

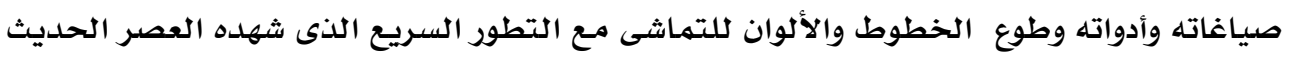

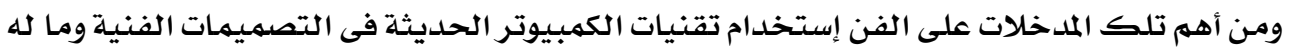

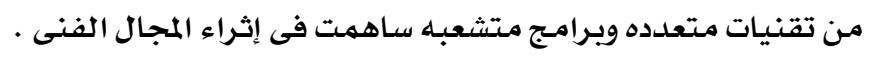

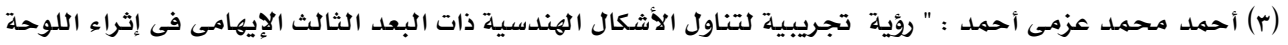

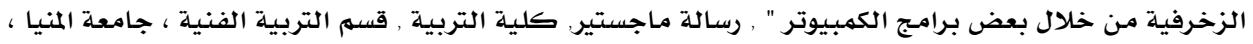

(1) Fatma Ismail: 29 ARTISTS in the museum of Egyptian on Modern art, AICA national section of Egypt, 1995, P53. 


\section{تعريف الكمبيوتر و أهميته :}

الكمبيوتر هو آلة تقوم بتتفيذ مجموعة من العمليات حسب قواعد معينة رسمت له سلفا

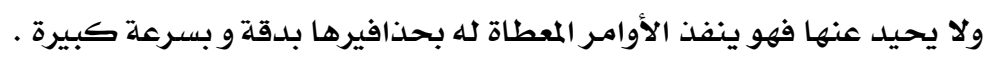

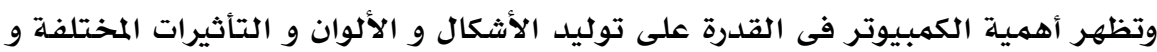

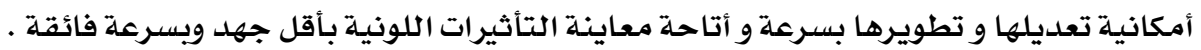

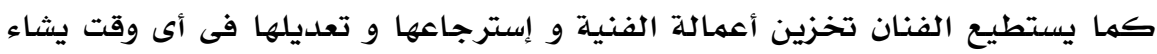

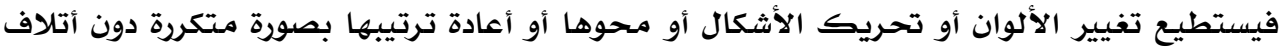

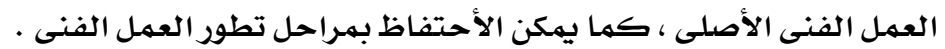

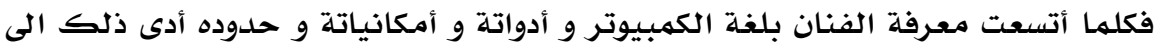

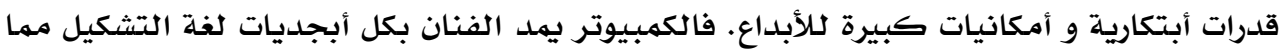

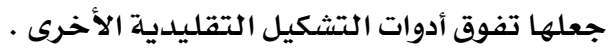

\section{دور التكنولوجيا وأثرها فى تصميه اللوحة الزخرفية لونية}

أن تأثير تكنولوجيا الكمبيوتر خاصلة فى التربية الفنية كان تاثيرا مذهلا حقا فقد طرأت

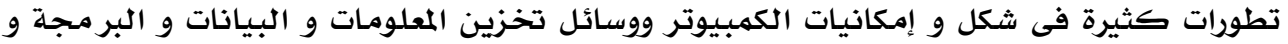

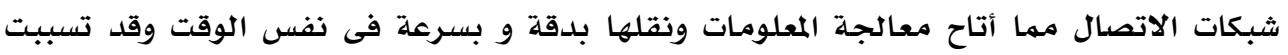

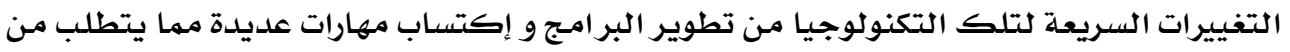

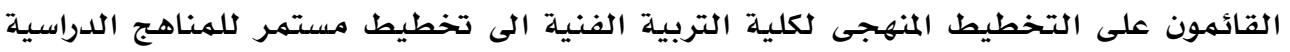

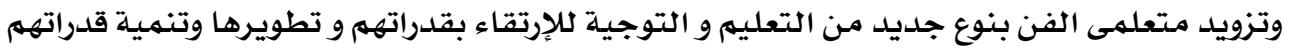

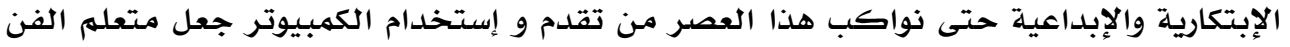

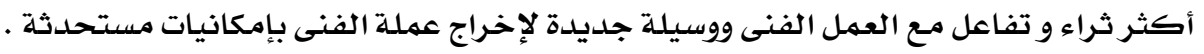

\section{إمكانيات الكمبيوتر في تصميي اللوحة الزخرفية :}

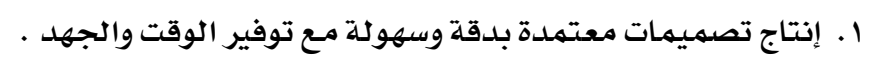

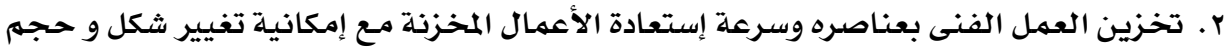

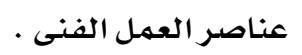

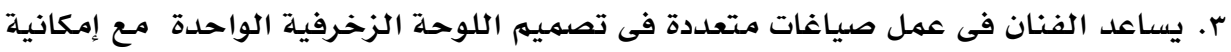

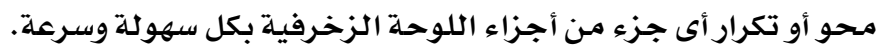

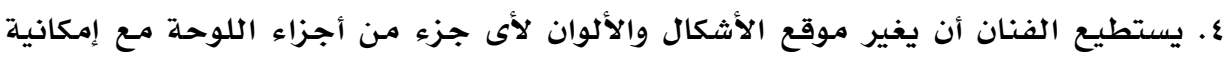

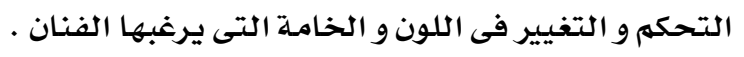

ه. يوفر الكمبيوتر أدوات تشكيلية كثيرة تساعد الفنان على أنتاج أعمالة الفنية بسهولة

$$
\text { وبسرعة. }
$$

7 . . يتيح إمكانية خلط الألوان بدقة كبيرة و الحصول على درجات متعددة للون الواحد . .

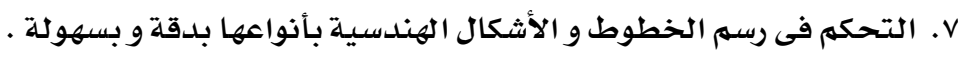


^. يتيح للفنان إستخدام مصادر أضاءة و الظل و النور ووضع خلفيات متعددة التى تناسب

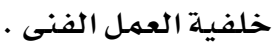

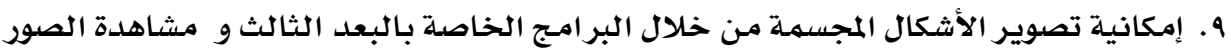

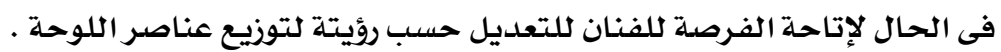

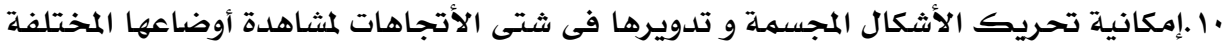

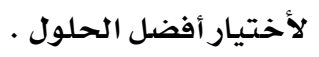

\section{أهم برامج الكمبيوتر التى يتم إستخدامها المعالجات التصميمية :}

\section{- برناهم الفوتوشوب Photo Shop -}

يرجـع السبب فى إختيار هذا البرنامج نظراً لإمكاناته المتعددة من خلال الأدوات الكثيرة

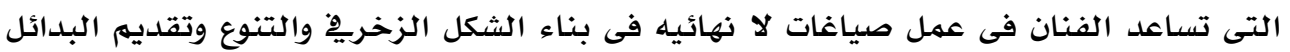

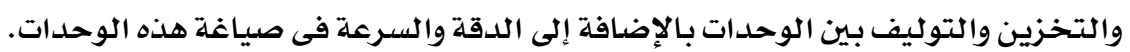

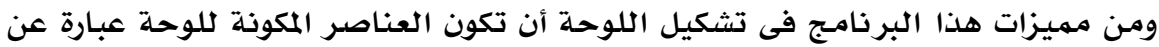

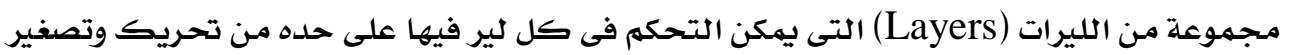

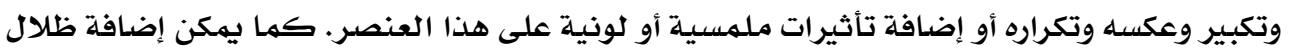

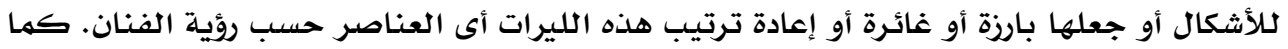

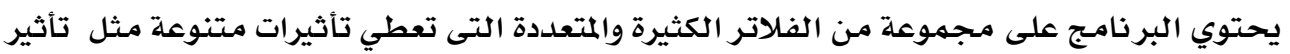

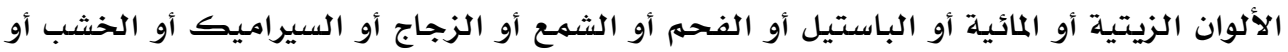

كما يهكن إضافة إضاءات متنوعة ملونة على الأشكال المكونة للعمل الفني. كما يمكن

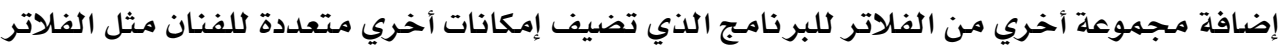

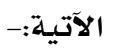

Photo Tools

Photo Optics

DrVirtigo
Extensis

Digimarc

Andromeda
Eye Candy

KPT

Flaming Pear 


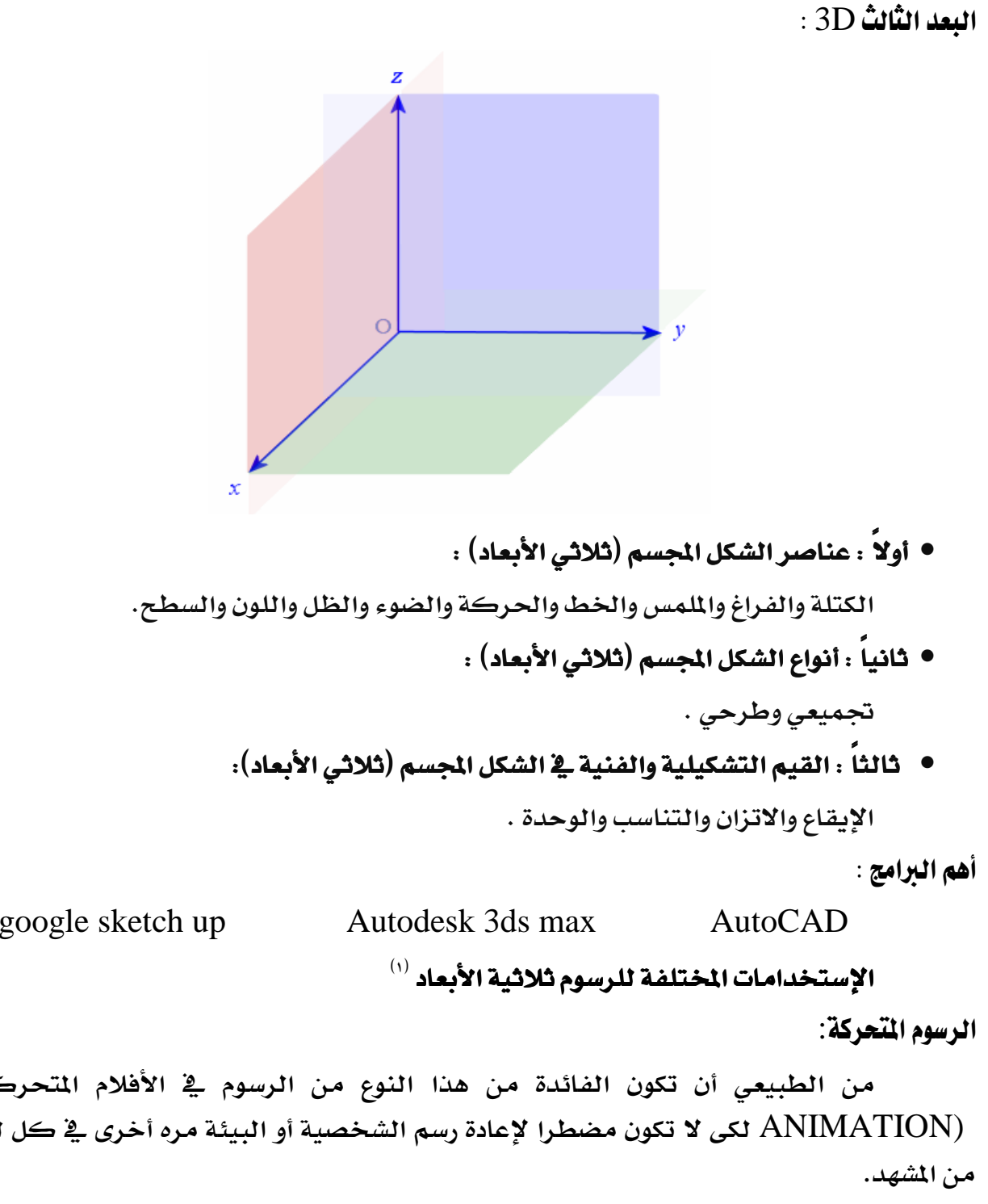

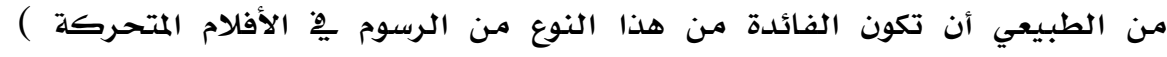

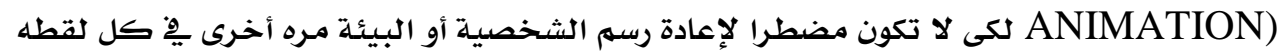




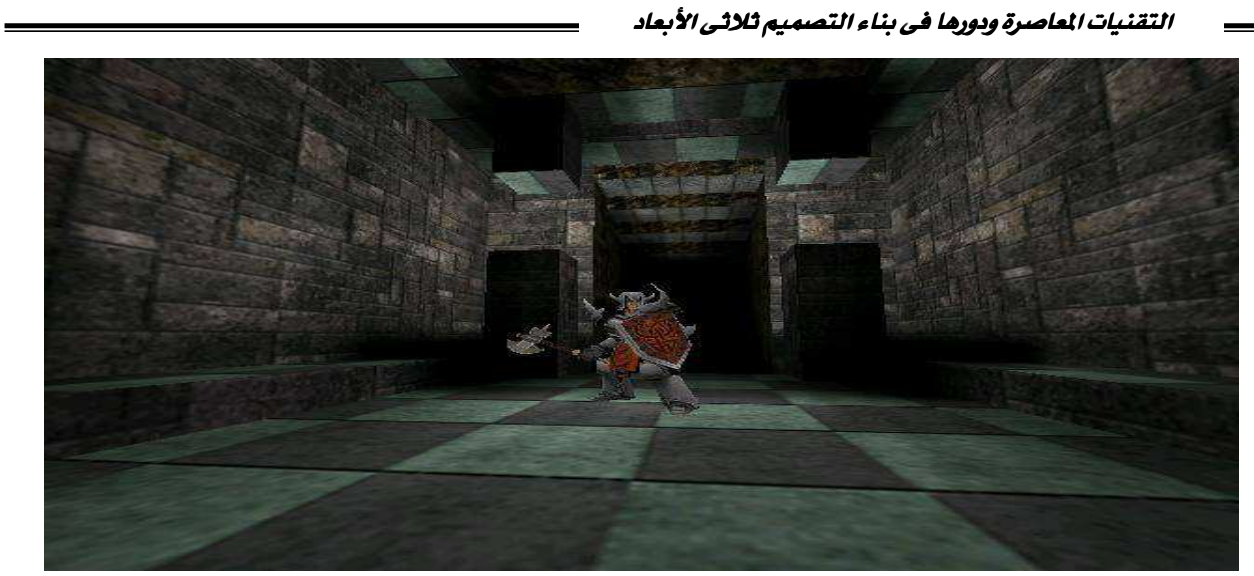

الأفلام السينمائية :

لقد وفرت تقنية الثري دي الكثير على المنتجـين فِ دور السنما العالميـة حيث أصببح من السهل إختلاق مشهد لكارثه طبيعية كزلازل أو أعاصير أوفيضانات وكذلك الإنفجارات وغيرها كما نشاهدها يِ الأفلام الحديثة دون أن يتعدى هذا منصدة العمل أو كمبيوتر مصهم هذه الكارثة

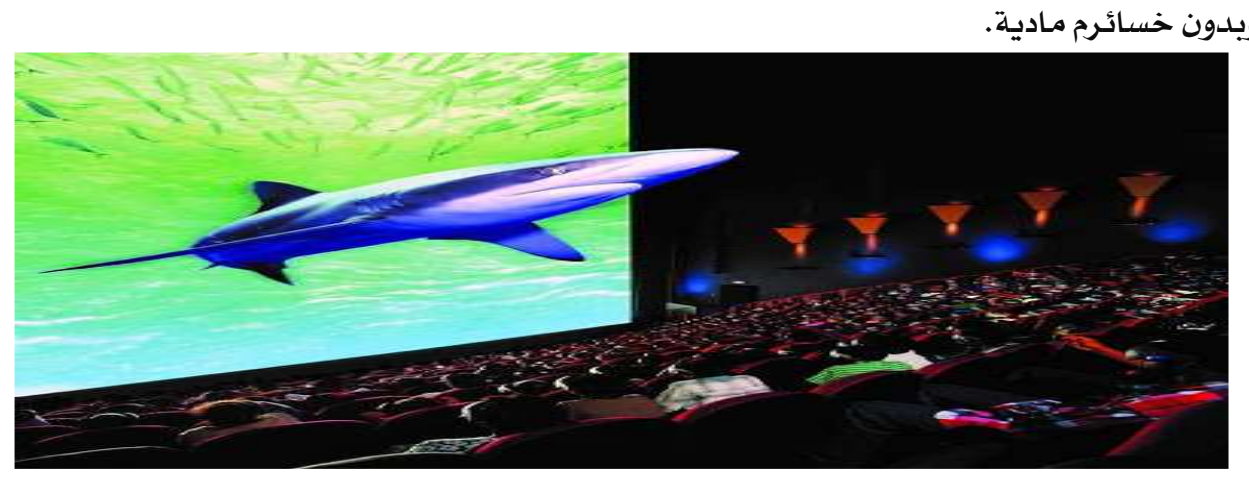

الإعلانات التجارية:

لا يكاد إعلان تلفزوني حديث يخلو من خلدع ورسومات ثلاثية الأبعاد ولقد تم الإتجاه لهذا

النوع من الرسوم لأن المصهم يجد حرية يِّ تصوير فكرة الإعلان بشكل أسهل من غيره . 


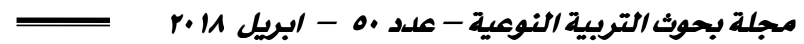

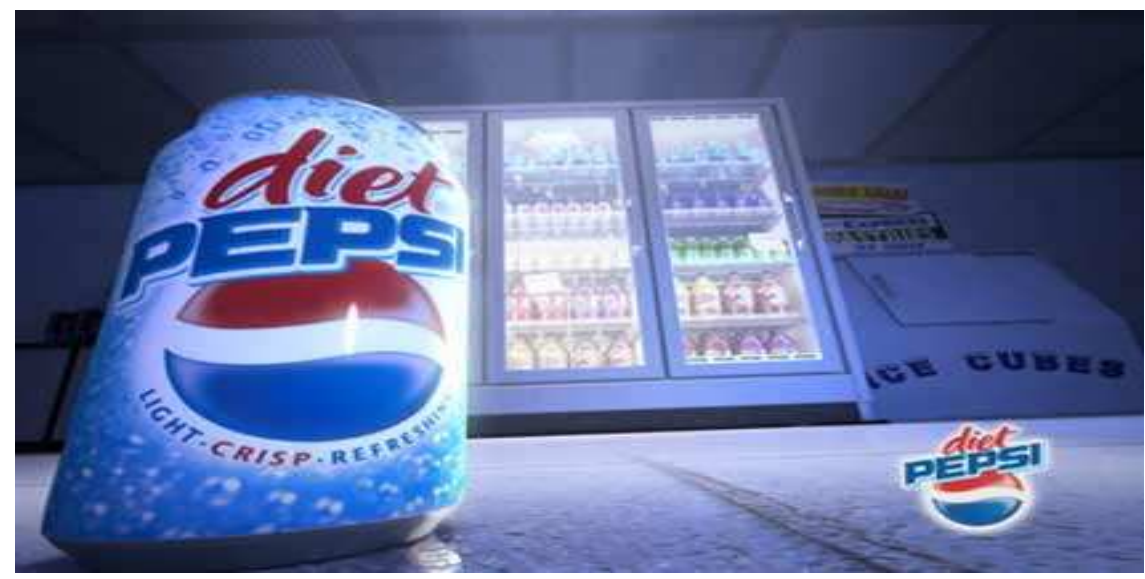

العماره والديكور:

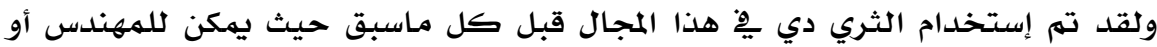

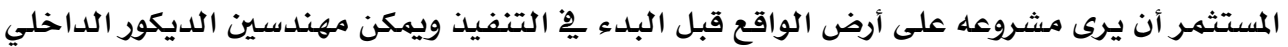

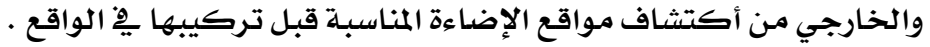

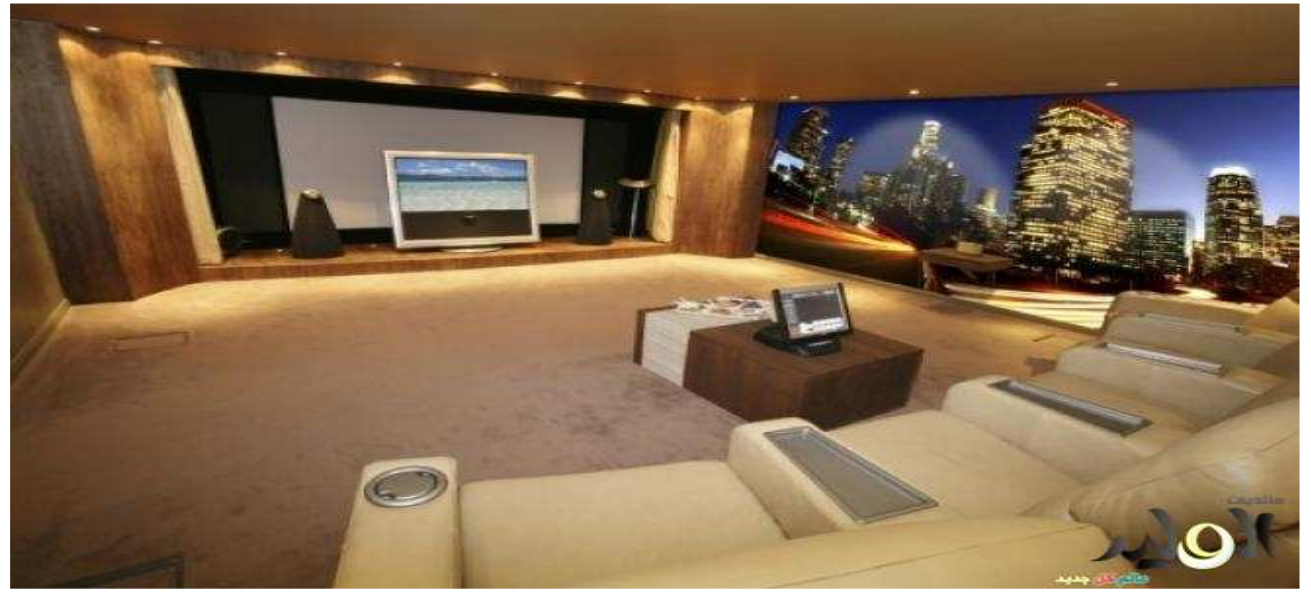




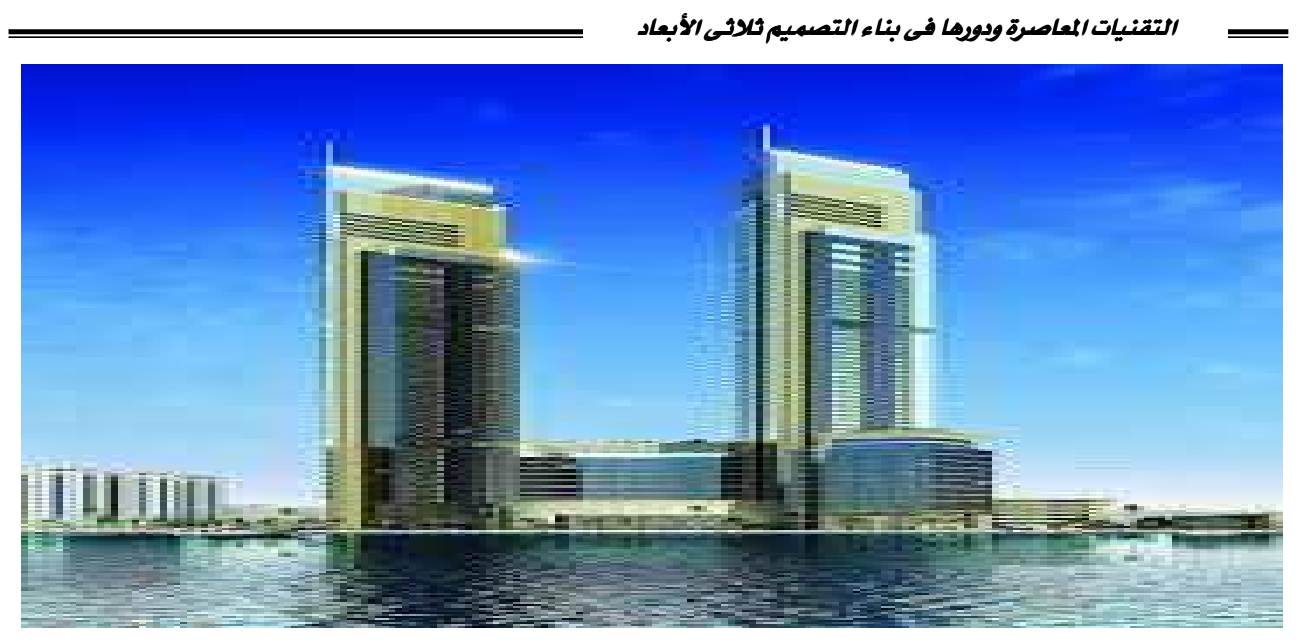

الصناعة والتطوير:

أصبحت برامج الثري دي هي المكان المناسب للإختبارات الأولية لاغلب المنتجات الصناعية

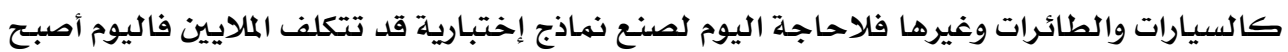

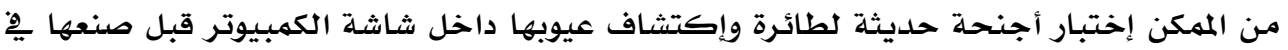

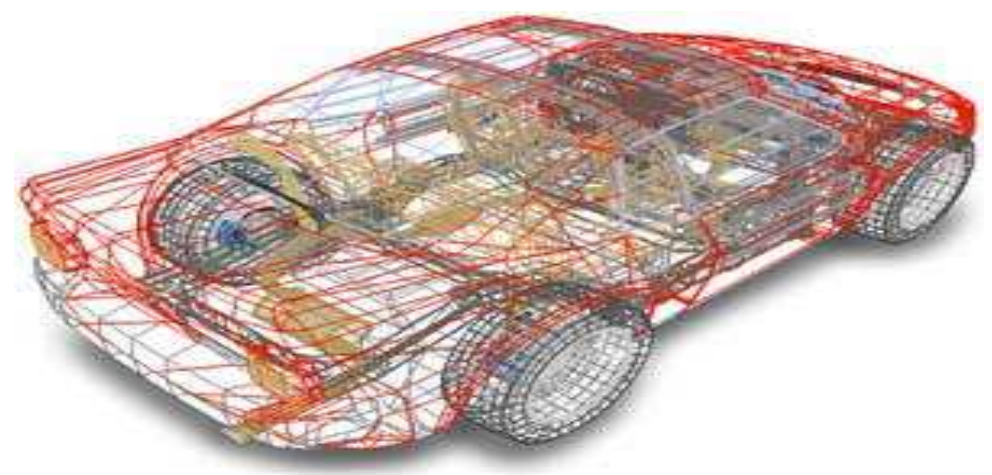

الواقع.

اللوحات التقليديه:(art) :

لازال الكثير من عشاق الرسم التقليدي يتحفونا بلوحات مدهشه بواسطه برامـج الثري دي. 


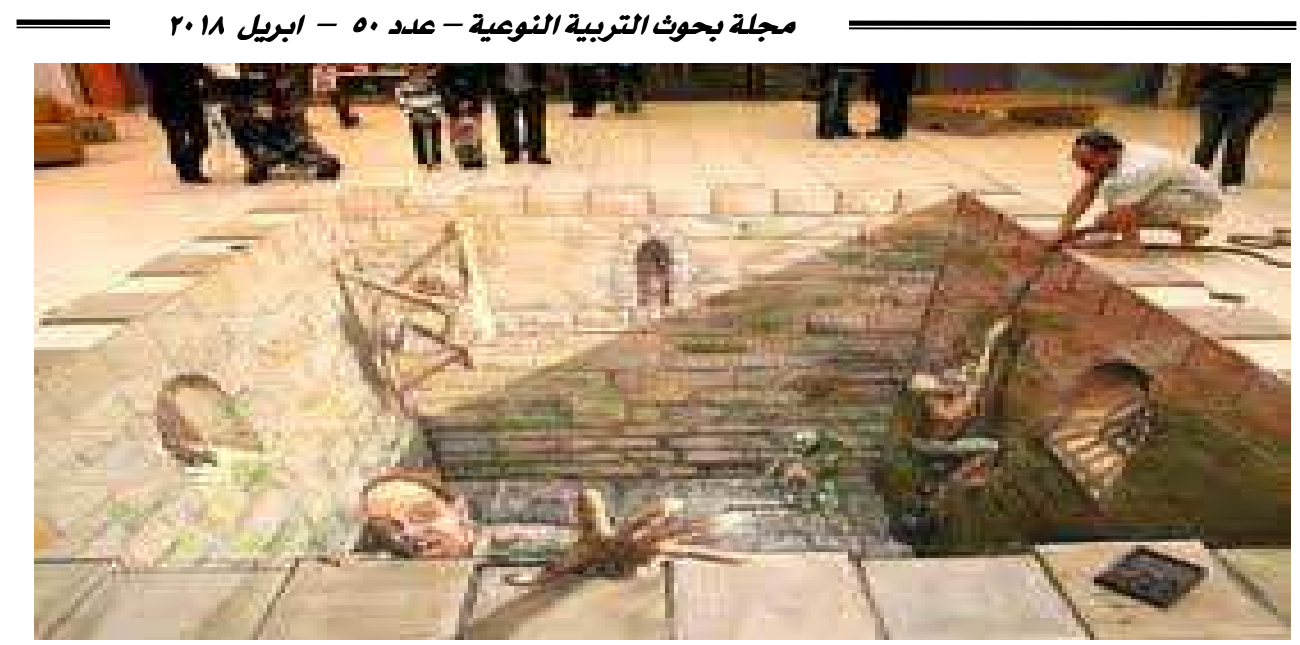

العلوم والتاريخ والخيال العلمي:

أ صبـحنا نرى أفلام وثائيقية للديناصورات بشكلها الطبيعي وكيف كانت تعيث حسب

مايراه العلماء يِ هذا المجال وكذلك كيف تم بناء الأهرامات وكيف تشكلت القارات وكيف تحدث التغييرات الكونية من حوادث وإنفجارات تبعد عنا آلاف السنيين الضوئيية ولم نكن لنراها لولا برامـج الثري دي.

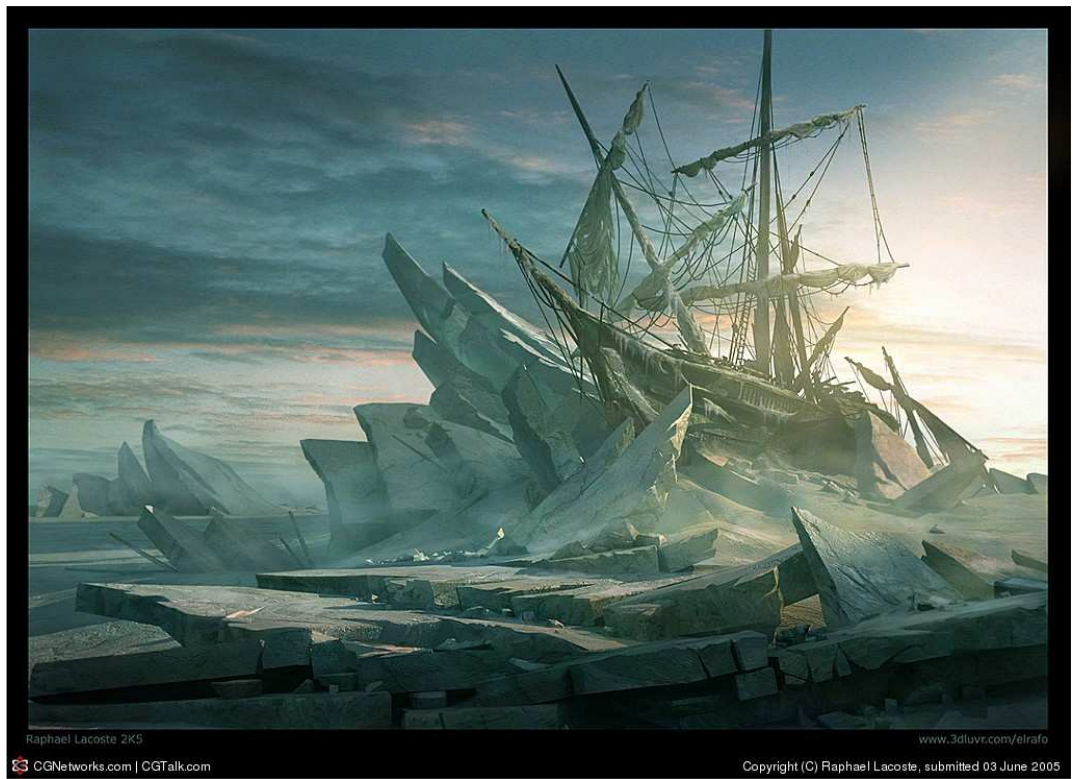

D Studio MAx3 FUNDAMENTALS ${ }^{\top}$ Michael Todd Peterson : ${ }^{2(}$ 
ا ـ التتأكيد على ضـرورة الإستعانة بتقنيـات التكنونولوجيا الحديثة فى مجال الفنون التشكيلية . r. توضيح طرق التعامـل مـع الوحدة الزخرفية الواحدة والحصول على عدة وحدات متنوعة من خلال خلال تقنيات الكمبيوتر ثلاثية الأبعاد . r. طرح مداخل متتنوعة لتعدد الصياغات التصميميـة للعنصر الواحد فِ مختارات من الفنون

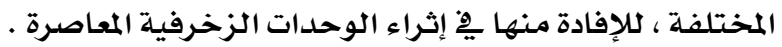
ع. العهل على الربط بين الفنون القديهة والحلديثة كوسيلة للحفاظ على هويتنا الفنية وإثرائها وتحقيق عنصر الإستمـرارية . ه. يسهم هذا البحث فى الكشف عن صياغات وحلول جديدة مبتكرة للوحة الزخرفية من خلال تقنية البعد الثالث .

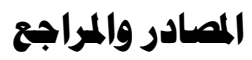
أولا :الكتب العلمية :

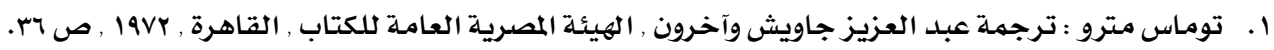

2. Dorthea : Design Elements and principles, U.S.A , 2005 . (2)

3. Fatma Ismail: 29 ARTISTS in the museum of Egyptian on Modern art, ICA national section of Egypt, 1995, P53.

4. D Studio MAx3 FUNDAMENTALS. r(4) Michael Todd Peterson :

\section{ثانيا: الرسائل العلمية :}

ه. إيمان محمد زكى : " الإمكانات الملمسىلة للمعالجات السطحية والإستفادة منها فى إثراء الأسطح

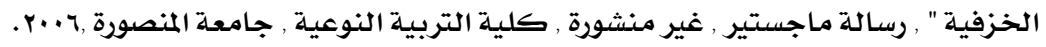

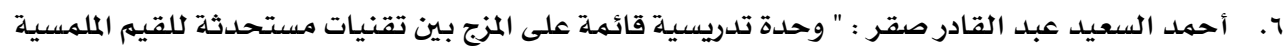

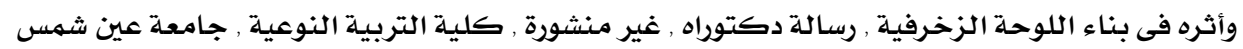
.r... V. محي الدين السيد احمد: الإمكانات التشكيلية لاستخدام المربع بِّ التصوير الحديث، رسالة دكتوراه،

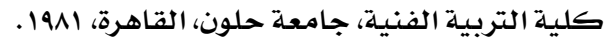
1. روز رأفت زكي : تقنيات تصوير ما بعد الفن الحديث لإثراء التعبير الفني، رسالة ماجستير، كلية التربية الفنية، جامعة حلوان، 1990.

9. منى صلاح مخلوف محمد : " أساليب وبرامجا الكمبيوتر في أعمال الجرافيك " , رسالة ماجستير , كلية الفنون الجميلة , جامعة المنيا , 1999. • ا . فيرا فايز حبشى : " برامج الحاسب الآلى وأثرها فى التصميم الجرافيكى المرئى ", رسالة ماجستير, كلية

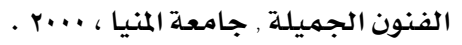




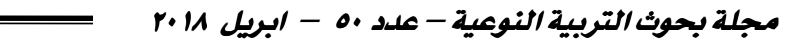

الـ أمل محمد فهمى محمود بحيرى : " التوظيف الجرافيكى لبصريات الخامـة وأثره على جماليات

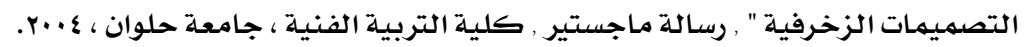

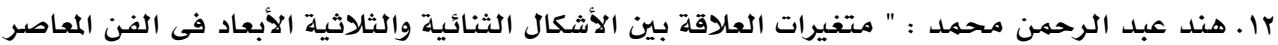

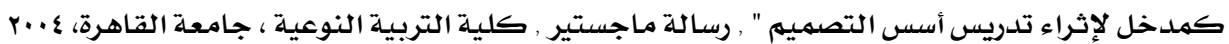
ثالثا :مواقع شبكة الإنترنت : http://www.Wikipedia.org 
Modern technology and its role in building a three-dimensional design

\section{Abstract}

The research tackled about the importance of innovative design and the foundations of design based on contemporary technologies and the advantages of modern technology techniques in obtaining three-dimensional design formulations of heritage heritage, emphasizing the true third dimension of the artistic work, and identifying the most suitable treatments and methods that can be followed with decorative units to extract Including new formulations of a contemporary nature. The research ends with the need to pay attention to contemporary technologies and technological treatments and employ them technically and educationally to benefit the recipients, artists and society, with a focus on the development of technical education in line with the Advanced skills and scientific discoveries, so that we can come up with an innovative society technically and scientifically. 